\title{
Exploring the potential of heat as a service in decarbonization: Evidence needs and research gaps
}

DOI:

$10.1080 / 15567249.2021 .1873460$

\section{Document Version}

Accepted author manuscript

Link to publication record in Manchester Research Explorer

\section{Citation for published version (APA):}

Britton, J., Minas, A. M., Marques, A. C., \& Pourmirza, Z. (2021). Exploring the potential of heat as a service in decarbonization: Evidence needs and research gaps. Energy Sources. Part B. Economics, Planning, and Policy, 1-17. https://doi.org/10.1080/15567249.2021.1873460

\section{Published in:}

Energy Sources. Part B. Economics, Planning, and Policy

\section{Citing this paper}

Please note that where the full-text provided on Manchester Research Explorer is the Author Accepted Manuscript or Proof version this may differ from the final Published version. If citing, it is advised that you check and use the publisher's definitive version.

\section{General rights}

Copyright and moral rights for the publications made accessible in the Research Explorer are retained by the authors and/or other copyright owners and it is a condition of accessing publications that users recognise and abide by the legal requirements associated with these rights.

\section{Takedown policy}

If you believe that this document breaches copyright please refer to the University of Manchester's Takedown Procedures [http://man.ac.uk/04Y6Bo] or contact uml.scholarlycommunications@manchester.ac.uk providing relevant details, so we can investigate your claim.

\section{OPEN ACCESS}




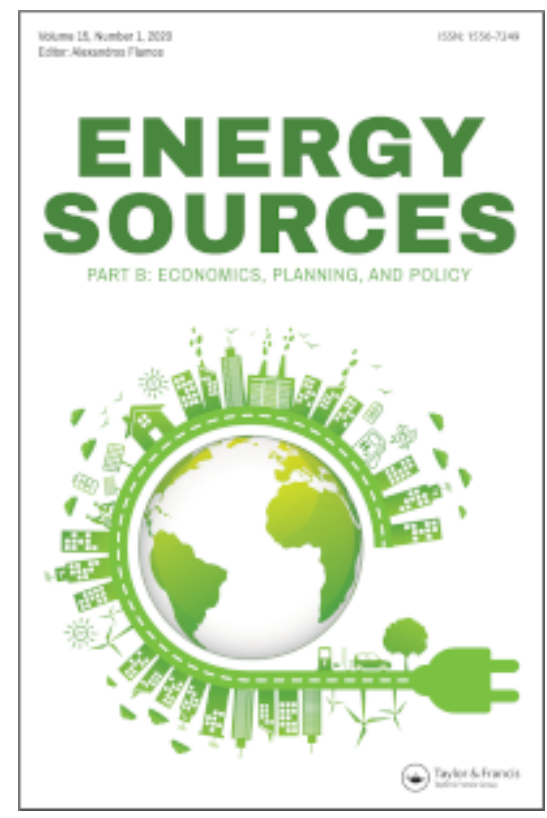

Exploring the potential of Heat as a Service in decarbonization: Evidence needs and research gaps

\begin{tabular}{|r|l|}
\hline Journal: & Energy Sources, Part B: Economics, Planning, and Policy \\
\hline Manuscript ID & UESB-2020-0265.R2 \\
\hline Manuscript Type: & Original Papers \\
\hline Keywords: & $\begin{array}{l}\text { heat as a service, heat decarbonisation, energy services, evidence } \\
\text { needs, smart heating }\end{array}$ \\
\hline \multicolumn{2}{|l}{} \\
\hline
\end{tabular}

\section{SCHOLARONE Manuscripts}




\section{Exploring the potential of Heat as a Service in decarbonizsation: Evidence 2 needs and research gaps}

\section{Abstract}

5 The need to accelerate the decarbonisationdecarbonization of heating, as well as the rise of

6 the 'smart home', mean that there is an increasing focus on the role of innovative consumer

7 offerings in driving the shift to zero carbon domestic heating. In this context, Heat as a

8 Service (HaaS) business models, which provide consumers with an agreed heating plan rather

9 than simply paying for units of fuel, are receiving increased attention. This paper explores

10 HaaS based on insights from facilitated group discussions with key stakeholders, and learning

11 from HaaS trials, in the United Kingdom. Results identified evidence needs and research gaps

12 related to: addressing issues of trust between consumers and suppliers, supportive policies,

13 financing business models, and openness and interoperability of technology and data. Based

14 on the findings, we propose policy and research recommendations to better understand the

15 role of HaaS business models in decarbonisationdecarbonization.

16 Keywords: heat as a service, heat decarbonisationdecarbonization, energy services, evidence

17 needs, smart heating

\section{Introduction}

19 It is widely acknowledged in academic and policy landscapes that urgent and radical heat

20 decarbenisationdecarbonization is essential to reducing greenhouse gas emissions compatible

21 with the $1.5^{\circ} \mathrm{C}$ mitigation pathway (IPCC 2018; IEA 2019; Knobloch et al. 2019). However, 
1 decarbonisingdecarbonizing heating continues to be a big challenge. The sector remains

2 dominated by fossil fuels, with recent data from 2018 showing that it contributes $40 \%$ of

3 carbon dioxide emissions globally (IEA 2019). Yet, it is imperative to meet current demands

4 for heating - which as of 2018 accounts for $50 \%$ of global final energy consumption - in

5 order to support industrial and commercial processes, as well as provide space and water

6 heating for homes and buildings (IPCC 2018; IEA 2019;). Within Europe, a number

7 efnumerous policy initiatives and programmesprograms have been put in place to support

8 heat decarbonisationdecarbonization. These include, for example:

9

10
- the European Union's Heating and Cooling strategy (European Commission 2016) which provides a framework to improve heating efficiency, for example by using low carbon technologies and smart systems;

- the revised EU Renewable Energy Directive (2018/2001/EU) which sets an annual target of $1.3 \%$ increase in share of renewables for the heating and cooling sector from 2021-2030; and

- the United Kingdom's (UK) Renewable Heat Incentive (RHI) which offers financial incentives for homeowners that adopt renewable heating technologies (Connor et al. 2015; BEIS 2018a).

However, progress in this sector remains slow. For example, in the UK, emissions from residential heating increased by $3.8 \%$ between $2017-2018$ due to compounding factors such as high demand during colder winters and slow uptake of low-carbon technologies such as heat pumps, biomass boilers and solar water heating (Chaudry et al. 2015; Hanna, Gross, and Parrish 2016; Committee on Climate Change 2019). More innovative solutions are therefore necessary to complement and strengthen current policies and technological options in order to accelerate heat decarbonisationdecarbonization. 
1 It is within this context that this paper explores the potential of Heat as a Service (HaaS) - a

2 business model innovation - in driving net zero carbon heating. In the HaaS model, energy

3 suppliers provide heat as a packaged service rather than simply as units of fuel. For example,

4 consumers buy an agreed level of warmth rather than kilowatt hours (kWh) of energy. By

5 'paying for warmth' consumers sign up for a heat contract, often termed a heat plan, that sets

6 a heating schedule for their home, hour-by-hour, and room-by-room using a smart heating

7 control system (Energy Systems Catapult 2019a). With the rise in connected homes and

8 digital technologies, service based-heating through HaaS may also support the deployment

9 of energy efficiency measures and low carbon technologies as increased incentives are placed

10 on the heat supplier to provide the agreed level of heating at the lowest cost (Energy

11 Technologies Institute 2018a).

12 Recent studies (Delta EE 2019a; Energy Technologies Institute 2019) have noted potential

13 benefits of service-based energy delivery models including simplifying complex future

14 energy markets, enabling consumers to access new low carbon technology and supporting

15 businesses to adopt demand side response mechanisms which help to reduce system costs.

16 HaaS is therefore seen to deliver positive impact to multiple stakeholders from policy and

17 industry as well as consumers. It is also regarded for its technology-agnostic approach to

18 decarbonisationdecarbonization - with flexibility to incorporate innovations in heat networks

19 (i.e., district heating), heat electrification and using hydrogen for heating (Energy Systems

20 Catapult 2019b). Countries such as Germany and Denmark have energy providers offering

21 HaaS since 2015 (Booth, Mohr, and Peters 2016; State of Green 2018; Amelang 2019);

22 whilst in the UK, the first HaaS trial was launched in February 2019, with new living labs in

232020 across England and Wales the Energy Systems Catapult (ESC) have been progressing

$24 \quad$ HaaS trials since 2018 (Energy Systems Catapult 2020). 
1 Given the need to rapidly decarbonisedecarbonize heating, there is considerable interest in

2 the potential of HaaS. However, there is currently limited evidence on how business models

3 such as this might develop, the extent of their contribution to heat

4 decarbonisationdecarbonization, and the challenges around consumer engagement,

5 technology, and regulatory or policy needs for a wider roll-out.

6 Against this background, this paper seeks to unpack current evidence needs and research gaps

7 to understand HaaS, and its role in decarbonisationdecarbonization. It draws upon a

8 stakeholder workshop conducted in the UK in September 2019 with heat sector participants

9 from academia, industry, civil society, and government. We begin with a review of literature

10 on energy services and current knowledge on Heat as a Service. We then describe the

11 methodological approach used to elicit insights from the participants in the workshop. Results

12 were analyżsed and categorizsed based on discussions around opportunities, evidence needs,

13 and research gaps that HaaS presents across (1) behaviourbehavior change and consumer

14 concerns, (2) policy and regulation, (3) technology, data and analytics and (4) business

15 models and financing. Finally, we conclude and propose recommendations for stakeholders

16 in policy, industry, and research.

17 2. ConceptualisingConceptualizing energy services

18 Whilst we define HaaS above as the provision of heat as a packaged service, i.e., consumers

19 buying an agreed level of warmth rather than as units of fuel, it is significant to note that

20 there is a considerable debate in relation to the wider concept of energy services. The term

21 'energy services' is utilisedutilized across a variety of contexts and disciplines with a wide

22 range of differences in eonceptualisationconceptualization. Much of the literature

23 emphasisesemphasizes that people demand and derive wellbeing from the services provided 
1 by energy rather than energy carriers themselves; however, beyond this overarching

2 similarity, applications of the term are diverse (Fell 2017; Kalt et al. 2019).

3 Fell's (2017) content analysis and review of the energy services literature identified 27

4 definitions of “-energy services”-

5 generally mutually exclusive, themes occurred most often:

6

7

8

9

10 Indeed much of the diversity in the energy services literature concerns differing conceptions

1. -Useful energy/work': the idea that energy services constituted “-useful energy"- or "-useful work"” in a way that is distinct from the energy use itself.

2. 'Benefit”: the idea that energy services entail some kind of “-benefit”- for human wellbeing.

18 Building on this definition, Morley $(2018,567)$ extends a sociological

19 eonceptralisationconceptualization of energy services and develops, based on Shove (2003),

20 a concept of “--meta-services"-- which takes a wider practice-based view of energy services to

\footnotetext{
${ }^{1}$ Sometimes referred to as final services or capabilities.
} 
1 incorporate "“cultural services', such as eosinesscoziness and cleanliness, that just happen to

2 depend on energy". Demand for energy-services is therefore an outcome of meta-services and

3 there is scope for the introduction of more efficient, alternative heating and cooling

4 technologies to underpin the emergence of different expectations and experiences of comfort

5 e.g., for heat pumps to be used for cooling or to keep temperatures higher. She argues for

6 increased exploration of the meanings of service and the ways in which these evolve and

7 proposes that whilst it is technically possible to deliver contracted levels of heating or cooling

8 service to householders, this is not the case with comfort. Since "comfort depends on a

9 diverse range of 'ingredients' across multiple systems of provision... (elothing, diet,

10 activities, furnishings and so on) even coalitions of utility companies and housing providers

11 may find it impossible to orchestrate and re-negotiate such diverse configurations in more

12 efficient ways" (Morley 2018, 567).

\section{3. Current knowledge on HaaS}

15 To provide context for this research, this section presents current knowledge on HaaS based

16 on a review of academic and grey literature, experiences and outcomes of HaaS trials,

17 existing business models in practice, and studies on the role and perceptions of consumers to

18 new energy business models.

\subsection{Academic literature on HaaS}

21 Although there has been a rapid increase in-policy interest in delivering heat as a service in

22 recent years $\underline{\mathrm{HaaS}}$ is rapidly increasing (see for example BEIS 2018b; Delta EE 2019b), there 
1 remains a very small amount of academic research that specifically engages with such

2 business models, their policy needs or societal implications. A Scopus search of peer-

3 reviewed literature in English in May 2020 returns just one reference to heat as a service

4 (Sovacool and Martiskainen 2020), which although focussedfocused on heating

5 transformations only includes heat-as-a-service as a keyword and does not discuss the

6 concept within the main body of the article 2 .

7 Expanding the literature review to include the terms "energy as a service" and "energy

8 services" reveals a much broader literature of almost 13,000 documents, almost exclusively

9 employing the term “energy service[s]”. In common with Fell's (2017) review of the energy

10 services literature, much of this current scholarship is focussedfocused on a number of

11 overlapping contexts, defined as:

12 - service based renewable energy programmes in Global South contexts e.g., leasing

13 packages for solar photovoltaics in Kenya (e.g. Adwek et al., 2019). This also

14 includes work related toon energy access where the term 'modern energy services' is

15 commonly employed;

- Energy Service Companies (ESCos) that contract with large public and private sector consumers to supply energy services rather than billing directly for energy used (e.g. Hannon and Bolton 2015; Lombardi, Pazienza, and Rana 2016; Capelo, Ferreira Dias, 19 and Pereira 2018);

- energy modelling studies which seek to examine the role of energy service demands (e.g. Fujimori et al., 2014);

\footnotetext{
${ }^{2}$ Search performed in Scopus, using query: TITLE-ABS-KEY ( "heat as a service" OR "heat-as-aservice")
} 
1

2

3

4

5

6

7

8

9

- research relating to energy efficiency or the rebound effect (e.g., Sorrell and

Dimitropoulos, 2008);

- the smart use of flexibility assets (such as storage) to manage network operation (e.g., Sarangi, Dutta and Jalan, 2012; Selim et al., 2017);

- explorations of how utility business models might develop as energy system decarbonisationdecarbonization progresses (Bryant, Straker, and Wrigley 2018; Hall et al. 2020);

- a considerable body of research considering the social drivers for energy demand and use (e.g., DellaValle, 2019; Strydom, Musango and Currie, 2020)

10 The ESCo literature may initially appear to be the most relevant to discussion of domestic

11 HaaS models, and there is an established literature relating to service-based energy contracts

12 in large public and private sector erganisationsorganizations (for example Hannon, Foxon,

13 and Gale 2013; Suhonen and Okkonen 2013; Bolton and Hannon 2016; Boza-Kiss and

14 Bertoldi 2019). However, Nolden, Sorrell and Polzin (2016) found little evidence that energy

15 service contracts have moved beyond well-established technologies to deliver innovative

16 solutions with lower rates of return. Additionally, these models for energy efficiency

17 improvements have not historically had much success in the residential sector due to the lack

18 of economies of scale, difficulties in access sufficient data ${ }_{2}$ and the complexities of consumer

19 behaviourbehavior (Rai, Reeves, and Margolis 2016; Cleary and Palmer 2019).

20 Literature on residential retrofit financing provides some insights into how service-based

21 approaches could engage consumers with Brown, Sorrell and Kivimaa (2019) exploring how

22 the design features of financial mechanisms for residential retrofit influence the success of 
1 business models. They suggest that mechanisms that reduce complexity by-simplifying the

2 consumer journey are likely to achieve much higher levels of uptake but that finance alone is

3 unlikely to be a-driver of demand for whole-house retrofit, and so instead-should be viewed

4 as a necessary-component of a much broader retrofit strategy.

\section{$5 \quad 3.2$ HaaS models in practice}

6 The academic and grey-literature specifically on HaaS is extremely small and few examples

7 of HaaS in practice are evident. The most substantive academic discussion of HaaS appears

8 to be by Skovshoved and Sandqvist (2017)in a Master's thesis on Industrial Engineering and

9 Management, which aims to identify service opportunities in the-heat pump business based

10 en a consumer value perspectivevalue propositions. It provides a description of a business

11 model offered in Denmark by a company called-Best Green. Best Green offers a service they

12 describe as HaaS whereby the end consumer pays for heat produced by the heat pump, an

13 annual service fee and initial installation costs but the heat pump is purchased and owned by

14 the company (Skovshoved and Sandqvist, 2017). The target audience includes householders,

15 municipalities and small commercial consumers with consumers benefiting from low heat

16 pump purchase prices due to bulk purchase and subsidies. The scheme aims to be simple, and

17 maintenance-free and remove hassle and risk for the end consumer, and reduce heat pump

18 purchase prices through bulk purchase.

19 Whilst the Best Green example is referred to as HaaS by both Best Green (State of Green

20 2020) and Skovshoved and Sandqvist (2017), organisationsorganizations may have differing

21 eonceptualisationsconceptualizations of what defines a HaaS business model with Delta EE

$22(2019 \mathrm{~b}, 1)$ suggesting such business models require service providers to take on five specific 
1 risks, "all of which (other than energy price risk) have historically been borne by the

2 consumer". They define these as:

3 - Financial risk - Credit risk of providing a heating appliance for little or no upfront

4 payment

5

- Technical risk - Routine maintenance and repairs for the heating appliance

6

- Performance risk - Efficiency of the heating appliance, the heat distribution system and the consumer's property

- BehaviourBehavioral risk - Impact of consumer behaviourbehavior on quantity and timing of heat demand

- Energy price risk - Fluctuations in wholesale energy prices

11 Under such definition, the Best Green offering does not require the service provider to take 12 on behaviourbehavior or energy price risk (as charges are made against $\mathrm{kWh} \underline{\underline{s}}$ of heat rather 13 than agreed temperatures) and is instead defined as "efficient asset leasing". Delta EE

14 (2019b) identified a trial in the Netherlands which takes on all five risks. The trial, by energy 15 supplier Eneco, involves consumers being charged for a fixed monthly fee for $20^{\circ} \mathrm{C}$ warmth 16 rather than heat generated. Limited details are available on how hot water is charged within 17 the contract. However, trials by the Energy Systems Catapult in the UK, discussed further 18 below, suggest that hot water tends to be incorporated on an unlimited basis in monthly heat 19 contracts.

20 In terms of research projects explicitly seeking to explore HaaS business models, only two 21 such projects were evident in the literature one in Denmark and one in the UK. The first was 
1 an ERA-Net Smart Grids Plus project "Markets, Actors and Technologies: A comparative

2 study of smart grid Solutions" (MATCH) case study in Denmark. The case study focused on

3 a demonstration project, GreenCom, which studied remotely-controlled demand side

4 management via heat pumps and photovoltaics (Christensen and Friis 2017). However, the

5 term HaaS appeared to be used as a synonym for remotely-controlled demand side

6 management (with defined maximum and minimum temperatures) and it is not clear whether

7 consumers paid a fixed price for the maintenance of an agreed temperature plan, as in a

8 'classic' HaaS model, or whether they actually paid based on kWh్ used (as in a

9 conventional energy-as-a-commodity model).

10 The second project was the Smart Systems \& Heat programprogramme-(SSH) run by the

11 Energy Systems Catapult (ESC) in the United Kingdom. Phase 1 of the SSH

12 programprogramme_included a trial of a consumer orientated Home Energy Management

13 System (HEMS) in 30 homes in 2016-17 which allowed multi-zone control of heating via a

14 consumer interface. The study revealed the extent to which comfort preferences are both

15 personal and contextual to the room type. Additionally, workshops with a sub-set of

16 participants and a control group explored how HaaS might work. The workshops indicated

17 that the majority of participants in the trial were enthusiastic about the idea of comfort and

18 cleanliness as services, rather than energy purchases, whereas the control group of consumers

19 were not enthusiastic about the idea of services (Energy Technologies Institute 2019).

20 The SSH programme also explored experiences of comfort in residential properties,

21 highlighting significant latent dissatisfaction and emphasisingemphasizing the complexity of

22 people's experiences of comfort. The project suggests that understanding the complex factors

23 influencing energy behaviourbehaviors and use are likely to be central to developing HaaS

24 models to ensure consumer propositions are viable and the risk of not meeting consumer 
1 service commitments are priced correctly. This will require extensive data on building

2 archetypes as well as from connected home devices. Such data would need to include insight

3 on efficiency of the fabric of the home, performance of major appliances such as boilers, the

4 way windows are used, the time of day when heat is needed most and so on (Energy

5 Technologies Institute 2018b).

6 Building on the learning from stage one of the SSH programme, the Energy Systems Catapult

7 The ESC then created a “"Living Lab"'- of 100 homes to test Heat as a Service during the

8 winter of 2017/18. Each household received advanced heating controls and the chance to buy

9 Heat as a Service in Warm Hours instead of kilowatt hours via Heat Plans (Energy Systems

10 Catapult 2019c). Heat as a Service propositions (Heat Plans) were chosen by around half of

11 trial participants and proved themselves attractive to a range of consumers and home heating

12 requirements. Trial participants valued better control of their domestic heat and costs but

13 chose to use this increased control in different ways, depending on their priorities (cost,

14 comfort, flexibility); however, almost all decided to heat fewer rooms (Energy Technologies

15 Institute 2018a; Energy Systems Catapult 2019b).

16 The trials produced a large volume of data on household needs and home energy performance

17 which enabled market segmentation based on temperature, space and timing of heat

18 requirements (Energy Systems Catapult 2019d). The 2017/18 field trial also indicated Heat

19 Plans or other service propositions-could increase consumers' openness to switch from gas

20 boilers to alternative-low carbon heating with $58 \%$ of participants open to the idea of having

21 an alternative low carbon heating system when replacing their gas boiler (compared to $36 \%$

22 of households in a segmentation survey of the wider population, $n=3,000$ ). This increased to

$2385 \%$ if participants could be given a guarantee that their current levels of comfort and cost

24 could be met (which was the aim of the Heat Plans) (Energy Systems Catapult 2019e). The 
1 field trial also explored issues of interoperability and identified key areas for future

2 development such as: commercially interoperable marketplaces, agreed open standards for

3 the use of domestic connected devices and data, alignment of physical trading approaches,

4 open data standards to allow for the movement of people's data, and appropriate approaches

5 to consumer protection (Energy Systems Catapult, 2019f). The ESC is continuing to trial

6 HaaS models, including working with municipal-supplier, Bristol Energy, to further

7 understand economically viable ways of offering HaaS (Energy Systems Catapult, 2020).

\section{$8 \quad 3.3$ The role of consumers in HaaS}

9 RecognisingRecognizing that digitalisationdigitalization and technological change mean the

10 retail energy market is expected to-evolvinge rapidly, the UK charity Citizens Advice

11 commissioned a series of reportsresearch on how such changes may impact en different types

12 өfconsumers (Crisp and Kruja 2019). The research identified some major barriers to

13 accessing offers in a future market, including digital exclusion, financial barriers, and issues

14 around-consumer engagement and trust. In particular they identify consumer confidence in

15 sharing data as a key issue in the development of HaaS models. A with a representative

16 survey of UK adults by Citizens Advice revealinged that $51 \%$ of respondents were not

17 comfortable sharing near real-time energy usage data (Crisp and Kruja 2019).

18 A study by Delta EE for Citizens Advice reviewed the opportunities and barriers for six

19 future business models in order to explore the opportunities and barriers likely to emerge in

20 the future energy retail market, including energy-as-a-service (EaaS) (Delta EE 2019a). They

21 suggest the biggest barriers to energy-as-a-service business models relate to (1) physical

22 aspect of the home (such as service standards not being guaranteed for unsuitable homes), (2)

23 changes in circumstance (leading to contractual uncertainty), (3) trust (the unfamiliarity of 
1 EaaS and the need for redress to be clear), and (4) digital literacy (those without digital

2 access or literacy being excluded). They also identified the benefits of EaaS for consumers,

3 energy networks and policymakers-as relating to their ability to simplify complex future

4 energy markets, enable consumers to-access to new low-carbon technologiesy and enable

5 demand-side response. An additional study for Citizens Advice convened workshops with

6106 consumers, who received information, and were asked about their views, on various new

7 energy retail models. Their research on heat as a service revealed people had mixed views of

8 this supply model. Consumers felt that homes need a high level of energy efficiency before

9 this model can be viable. The fear of losing control was a recurring theme and long-term

10 contracts were not popular. Whilst the length of HaaS contracts are likely to vary depending

11 on the extent to which efficiency and heat generation technology costs are incorporated into

12 monthly charges, indications from the commercial ESCo market suggest that performance

13 based contracts are typically between 5 and 15 years long (Lombardi, Pazienza, and Rana

14 2016). Participants were also concerned that less digitally-savvy consumers who are less

15 digitally-savy could be excluded from HaaS models-and were unclear on how problems

16 would be solved or routes to redress (Mulvey, McNab, and Morley 2019).

17 To date, there has been limited analysis of the equity implications of domestic energy- or

18 heat-as-as-service business models. RecognisingRecognizing the need for greater analysis of

19 these issues, Sovacool, Lipson and Chard (2019) analysedanalyzed the justice implications of

20 various domestic low carbon innovations and suggest that energy service contracts illustrate

21 some of the potential tensions between affordability and decarbonisationdecarbonization

22 benefits (as consumers contract for the same levels of comfort but at a lower cost and using

23 less energy) and equity concerns (as only some householders may be offered contracts).

24 However, the Energy Technologies Institute (2018b) propose that such service-based 
1 approaches could also allow policymakers to address fuel poverty through providing a route

2 for the government to target subsidies based on paying service providers by results. For

3 example, delivering improved affordability and thermal comfort would be the performance

4 measures for the payment of subsidies rather than the number of homes that are-insulated.

5 Overall, both energy-as-a-service and, more specifically, heat-as-a-service business models

6 are poorly defined in the literature. Additionally, while there are (1) a small number of key

7 projects and existing utilities exploring Heat as a Service business models, and (2)

8 established literatures exploring the key aspects of heating behaviors, practices, and energy

9 efficiency business models, there remains a very limited literature that systematically

10 examines the decarbonisationdecarbonization, human wellbeing, and policy implications of

11 HaaS models. This paper seeks to contribute to expanding this literature by offering insights

12 from stakeholders, elicited through the participatory research approach described in Section 134.

14 4. Methodology

15 In order to explore the evidence needs and research gaps to developing Heat as a Service 16 (HaaS), a stakeholder workshop was carried out in the UK in September 2019. Its aims were 17 to discuss current knowledge on HaaS, both-in the UK and internationally, andinternationally 18 and encourage debate about HaaS' potential as an energy delivery model. A total of 40 19 participants from academia, industry, civil society, and government sectors attended the 20 workshop (Table 1). Participants were identified through purposive sampling based on 21 information from literature on heat sector stakeholders in the UK, discussions with key 22 organisationsorganizations involved in HaaS trials and heat innovations in the UK, and 23 promotion through the UK Energy Research Centre. The discussions were 
1 contextualisedcontextualized by presentations from two industry participants that have led

2 HaaS trials in the UK and a consumer protection erganisationorganization that has carried out

3 research on energy business models.

$4 \quad$ [Table 1 near here]

5

6

Table 1. Workshop participants by sector

\begin{tabular}{ll}
\hline Sector & Number of participants \\
\hline Industry & 18 \\
Academia & 16 \\
Government & 4 \\
Civil Society & 2 \\
\hline
\end{tabular}

7

8 The workshop was structured using Ketso, a facilitation toolkit used in participatory planning

9 and action research used to facilitate group discussions-(Bates 2016; Wengel, McIntosh, and

10 Cockburn-Wootten 2019). This flexible-tool helps participants to visualisevisualize and order

11 their responses to questions and captures a record of individual responses and group

12 prioritisationprioritization of issues. Following the Ketso method, participants were divided

13 into five groups and asked to discuss the following questions:

14 - What work is already happening in HaaS?

15 - What are the ambitions and opportunities for HaaS?

16 - What are the barriers and knowledge gaps for the HaaS model?

17 - How can the barriers and knowledge gaps identified be overcome? 
1 Participants then wrote their ideas and placed them on central clusters around four key topics:

2 (1) behaviourbehavioral and consumer issues, (2) policy and regulation, (3) technology, data

3 and analytics, and (4) business models and financing. The groups then identified the issue/s

4 they believe to be most important for each question. This process allowed everyone to work

5 on their ideas in parallel and helped to obtain more structured results. Emerging themes from

6 each topic were analysedanalyzed, compared, and verified against the literature. These

$7 \quad$ findings are presented in Section 5.

8

9 5. Evidence needs, barriers, and opportunities for HaaS

10 This section presents the analysis of the themes that emerged from the stakeholder

11 discussions as well as insights from literature on HaaS. It discusses evidence needs, barriers,

12 and opportunities for implementing HaaS across four areas: behaviourbehavioral and

13 consumer issues, policy and regulation, data analytics and technology, and business models

14 and financing.

\section{$15 \quad 5.1$ Behaviour Behavioral and consumer issues}

16 With low carbon $\underline{A s}$ technologies such as heat pumps becoming more common, people's

17 perception of comfort is likely to change in the future-(Morley 2018). Offering HaaS

18 therefore has the potential to unlock better consumer experiences, i.e., warmer or cooler

19 homes, where the value proposition is a fixed price for heat over a set period, rather than

$20 \mathrm{kWh}$. As discussed, in Ssection 3, HaaS may also be able to stimulate carbon emissions

21 reductions from both reduced demand and service plans that integrate as-energy efficiency

22 and smart technologies-can be integrated into service plans. In addition, there is emerging 
1 evidence that HaaS business models may increase consumers' openness to new technologies

2 with the ESC (Energy Systems Catapult 2019e) Smart Systems \& Heat programme-Phase 2

3 field trial in the UK suggesting that people with experience of heat plans were more likely to

4 want a heat pump. The trial indicated that while less than $0.1 \%$ of people who read an on-line

5 advert wanted a free heat pump, more than $15 \%$ of people who took part in the trial were

6 interested.

7 Despite these potential benefits, workshop discussions revealed that energy is generally

8 viewed as a commodity rather than a service. Implementing HaaS will therefore be a

9 transformative challenge for both the energy provider and the consumer. Ultimately, there

10 was consensus amongst stakeholders that the HaaS system needs to be both fair, simple and

11 support the transition to a net zero carbon future. However, consumers are unfamiliar with

12 the HaaS concept and its value propositions and therefore show low interest. Stakeholders

13 suggested that a lack of awareness about HaaS is one the biggest barriers to its deployment.

14 This aligns with the findings of Citizen's Advice (Crisp and Kruja 2019) that the general lack

15 of awareness on low carbon technologies may prevent households from adopting energy

16 services.

17 Further research is needed to identify value propositions for different consumers and to

18 understand the consumer journey from considering HaaS to agreeing a contract and installing

19 energy efficiency and decarbonisedecarbonized heating technologies. In particular, additional

20 large-scale trials are required to explore consumer motivations and barriers and assist the

21 development of more detailed consumer archetypes. Whilst commercial suppliers may

22 develop such archetypes there is a need for regulators to also develop their understanding of

23 consumer segmentation in order to both regulate suppliers and protect consumers effectively. 
1 The ability of a home to achieve a certain level of comfort (or service expectation) is very

2 dependent on a range of factors such as the equipment installed, how it is configured, and

3 building efficiency. Buildings, and how they are used, vary enormously, even between those

4 of similar type, age and size and one study of 290 identical homes found that the highest used

5 twenty times as much heat as the lowest (Andersen 2012). As Delzendeh et al. (2017)

6 identify, a diverse set of factors influence energy behaviourbehaviors and further research is

7 required in order to better account for occupant behaviourbehavior in building energy

8 performance analysis.

9 There is also a need for the development of appropriate consumer protection measures to

10 ensure consumers understand the benefits and risks of complex service-based offerings and

11 have provision to adjust contracts if their circumstances change. The UK Heat Trust, which

12 acts as an independent consumer champion for heat networks, was cited by participants as an

13 example of a framework to hold suppliers to account and set expected standards. A review of

14 heat network business models may also provide some learning in relation to the provision of

15 service-based contracts.

17 Table 2 summarisessummarizes the barriers, evidence needs, and research gaps related to

18 behaviourbehavior and consumer issues identified during the workshop. The main barriers

19 eentredcentered on lack of consumer awareness of HaaS, digital literacy, the length of

20 contract with energy service provider and home efficiency. In order to address these, the

21 evidence needs and research gaps are highlighted to help define the way forward. [Table 2 near 22 here] 
1

10

11

12

13

14

15

16

17

18

19

20

21

22

23

24

25

26

27

28

29

30

31

32

33

34

35

36

37

38

39

40

41

42

43

44

45

46

47

48

49

50

51

52

53

54

55

56

57

58

59

60 
Table 2. BehaviourBehavioral and consumer issues for HaaS

Barriers

Lack of awareness about HaaS which

may lead to lack of trust in third-party

energy service providers

order to access HaaS energy settings (e.g., through applications that control alerts about usage)

Consumers currently value short term contracts (1-2 years) and the ability to change provider

\section{Evidence needs and research gaps}

- Research to identify value propositions

for different consumer segments

- Additional, large-scale HaaS trials to

understand consumer's motivations

and barriers

- Developing independent organisations

(e.g., UK Heat Trust) to protect

consumer's interests

- Developing and testing programmes to improve digital energy literacy in target populations

- Consumer research to explore the impact of presenting information temperature in each individual room and regarding the risks and benefits of contracts in various ways

Length of contract with energy provider 
Evidence needs and research gaps

- Consumer research across a wider

range of end user types and tenures

Energy use behaviourbehaviors

influenced by a diverse set of factors

related to occupant's energy use and

building energy performance

Lack of clarity about consumer's

willingness for disruption at home for

retrofit and renovation needed for HaaS

and guaranteed efficiency

Service companies might not guarantee

outcomes for energy inefficient homes

and there can be insufficient space to

install new equipment
- Interdisciplinary studies to understand

the interrelations between energy

demand, business models, data and

consumer behaviourbehavior

- Large-scale studies which consider the

impact of equipment type,

configuration, building efficiency and

use on the ability for service

expectations to be met

- Development of a communication tool

that integrates independent advice,

consumers, and installers to help

overcome consumer unwillingness for

home disruption due to retrofits

- TriallingTrialing HaaS as part of the

retrofit package with the supplier

coordinating energy efficiency retrofit, installation of new heating systems, controls, and financing. 
- Introducing a competitive system for saving carbon at various levels, i.e., individual, local and national to improve home efficiency

\section{$1 \quad 5.2$ Policy and regulation}

2 Policy and regulation are key to enabling low carbon technologies and emerging business

3 models whilst protecting consumer interests and ensuring social equity. The acceleration of

4 heat decarbonisationdecarbonization is intrinsically connected with new policies and

5 regulations that protect consumers, address fuel poverty, enable new revenue streams,

6 incentiviseincentivize low carbon solutions and increase resilience. The Energy Technologies

7 Institute argued that, although a shift to retailing energy services in place of units of energy

8 may well happen over time, it is unlikely to happen naturally at sufficient pace to establish

9 the conditions to decarbonisedecarbonize heat. Therefore, "commercial, policy and

10 regulatory opportunities will need to converge if such services are to play a role in

11 decarbonisationdecarbonization" (Energy Technologies Institute 2018a, 21).

12 Results from the workshop indicate that policy support will be needed at different stages of

13 HaaS development to meet the needs of consumers, suppliers, and the heat

14 decarbonisationdecarbonization agenda in a way that is equitable. Householders, for example,

15 need support to cover investment costs associated with retrofitting properties with energy

16 efficient and low-carbon heating technologies (e.g., heat pumps), and suppliers are unlikely

17 to be able to integrate financing for such measures into HaaS without supportive policies or 
1 incentives (Lakatos and Arsenopoulos 2019). Results from the ESC trials (Energy Systems

2 Catapult 2019b) also show that the financial viability of HaaS is not yet proven for both

3 suppliers and consumers.

4 There is a lack of comparative studies of the development of HaaS models across different

5 countries, and regulatory contexts, as well as the benefits and challenges of different varieties

6 of HaaS. As identified by Delta EE (2019b) there are several utilities already offering

7 services branded as HaaS across a number of European countries; however, the services

8 offered and the allocation of risk between supplier and consumer differ across models and

9 future studies could explore the impact of differing regulatory contexts, financing

10 mechanisms, and contractual arrangements.

11 Additionally, there is a lack of understanding of policy conflicts related to HaaS. For

12 example, in the UK there is growing interest in HaaS within policymakers (BEIS 2018b) and

13 some awareness of the need for longer-term contracts under such models. However, there is

14 also an ongoing faster switching programme which seeks to ensure reliable next day

15 switching by 2021 and potential misalignments between the two agendas are yet to be fully

16 explored. In addition, the development of HaaS is dependent on wider research on heat

17 decarbonisationdecarbonization including understanding how flexibility services and markets

18 will evolve.

20 Significantly, there is a need to address the potential for HaaS models to exclude some

21 householders (for example, due to physical aspects of the homeresulting in diffieulty in

22 guaranteeing service standards) and how such business models should be integrated with

23 energy efficiency subsidy programmes. As identified by Seebauer, Friesenecker, and Eisfeld

24 (2019) much climate and social policy across tends to be fragmented resulting in a lack of 
1 policy effectively targeted at the fuel poor and there are significant research gaps in

2 understanding how energy services business models impact on the fuel poor. Table 3

3 summarisessummarizes the policy and regulation barriers for the consumer, suppliers, and

4 heat decarbonisationdecarbonization, and highlights the respective evidence needs and

5 research gaps. [Table 3 near here]

6

7

Table 3. Policy and regulation challenges for HaaS

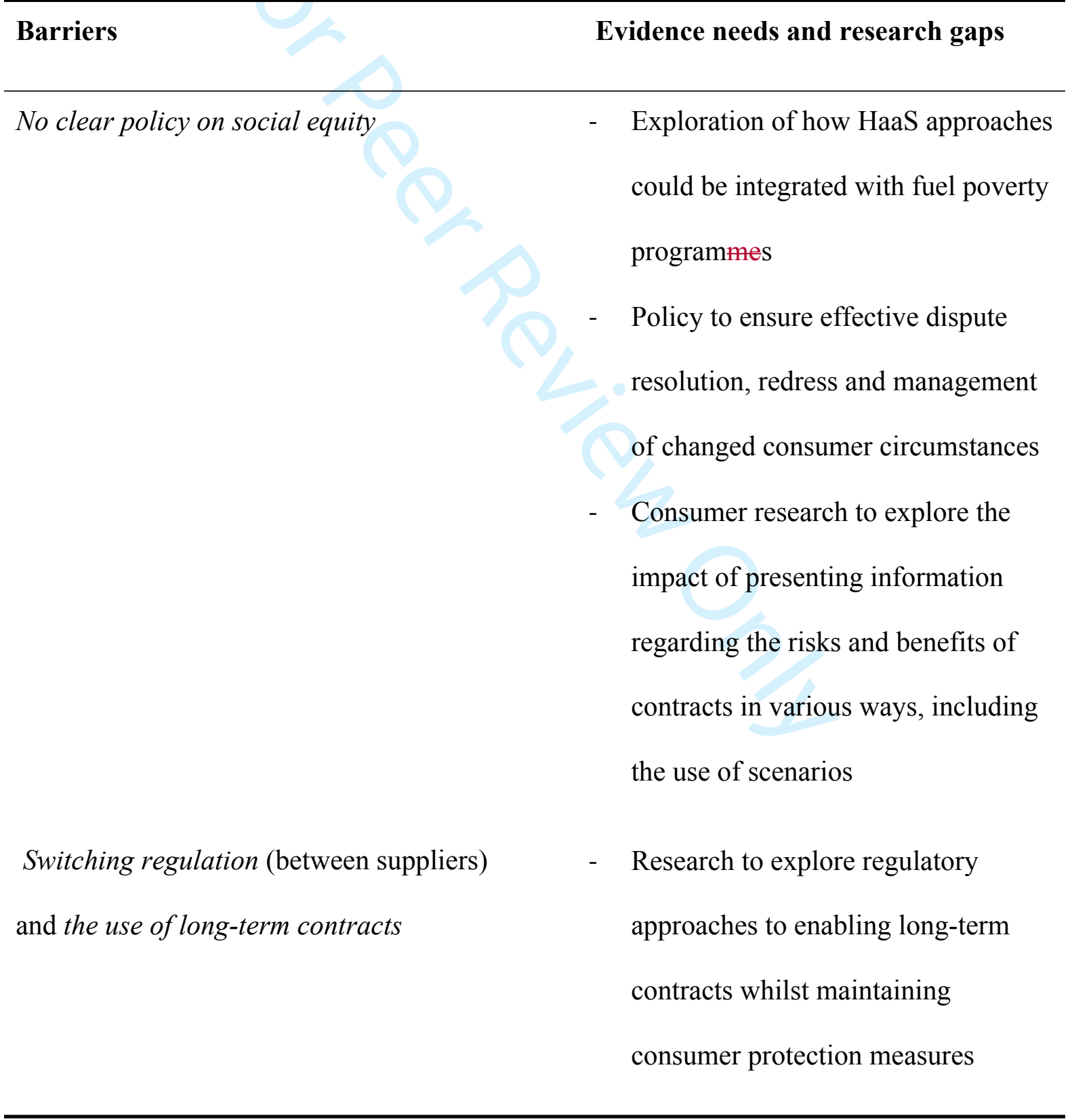


Evidence needs and research gaps

- New regulatory support for utility

bundles with rent, with an

appropriate competition framework

for providers

Supply Licensing conditions and tariff

rules tend not to be supportive of HaaS

20

21

22

23

24

25

26

27

28

29

Lack of comprehensive heat

and policies in many countries

Existing incentives are often

underperforming or not aligned. For

example, the extent to which the

assignment of rights within existing the UK) inhibits HaaS models is unclear.
- Review of supply licensing to align

future licenses and regulation with

evolving business models; this

would include the development of

more modular, principle-based

regulation to support innovation

- Further use and analysis of

regulatory sandboxes to test new

business models

- Conduct a full-scale review of the

decarbonisationdecarbonization strategy

policy and regulatory framework for heat, including assessment of how to create an attractive investment

climate for heat as a service business

models

- Investigate the effect of radical

subsidies programmes (such as the RHI in policies that ban gas or make it more 
Evidence needs and research gaps

expensive and carbon emissions

pricing

- Long-term subsidies and incentives

to accelerate heat

decarbenisationdecarbonization

1

$2 \quad 5.3$ Technology, data, and analytics

3 HaaS models require extensive collection of energy consumption data from households,

4 buildings and domestic connected devices, as well as information on consumer

5 behaviourbehavior, heating practices and needs. This data could inform the design of an

6 intelligent heating system that predicts how much heat each household needs, allowing

7 suppliers to provide services based on demand and offer more advanced heat

8 eustemisationcustomization. While these data and technology could provide benefits and

9 opportunities for heat service providers and consumers, these could also introduce more

10 challenges for both.

11

12 Developing open standard data and interoperable systems which could exchange data and

13 information, allow free public access, -and enable different services to work together is a new

14 challenge in this area. Additionally, more connected devices at domestic level could provide

15 opportunities for internal and external hackers to gain unathorisedunauthorized access to the

16 digital platform of the heating system. Finally, preserving consumer data privacy and trust

17 between consumers and providers should be considered as a high priority challenge for HaaS 
1 models. The trade-off between data privacy and developing a highly tailored offering is a

2 complex issue that needs to be further understood (Energy Technologies Institute 2018a).

3 Understanding (and pricing) the risk of energy uses not meeting expectations is particularly

4 central to HaaS models as the outcome (i.e., X number of warm hours) is guaranteed

5 regardless of the amount of energy actually used. To date, the Energy System Catapult trials

6 in the UK have provided the most detailed information on the issues associated with

7 developing HaaS models (Energy Systems Catapult 2019b, 2019c, 2019d). However, the

8 limited nature of existing trials means that there is significant uncertainty regarding whether

9 HaaS models will result in better consumer experiences (i.e., warmer, cheaper homes) which

10 are also lower carbon. Table 4 summarisessummarizes the barriers, evidence needs, and

11 research gaps related to technology, data, and analytics. [Table 4 near here]

Table 4. Technology, data, and analytics

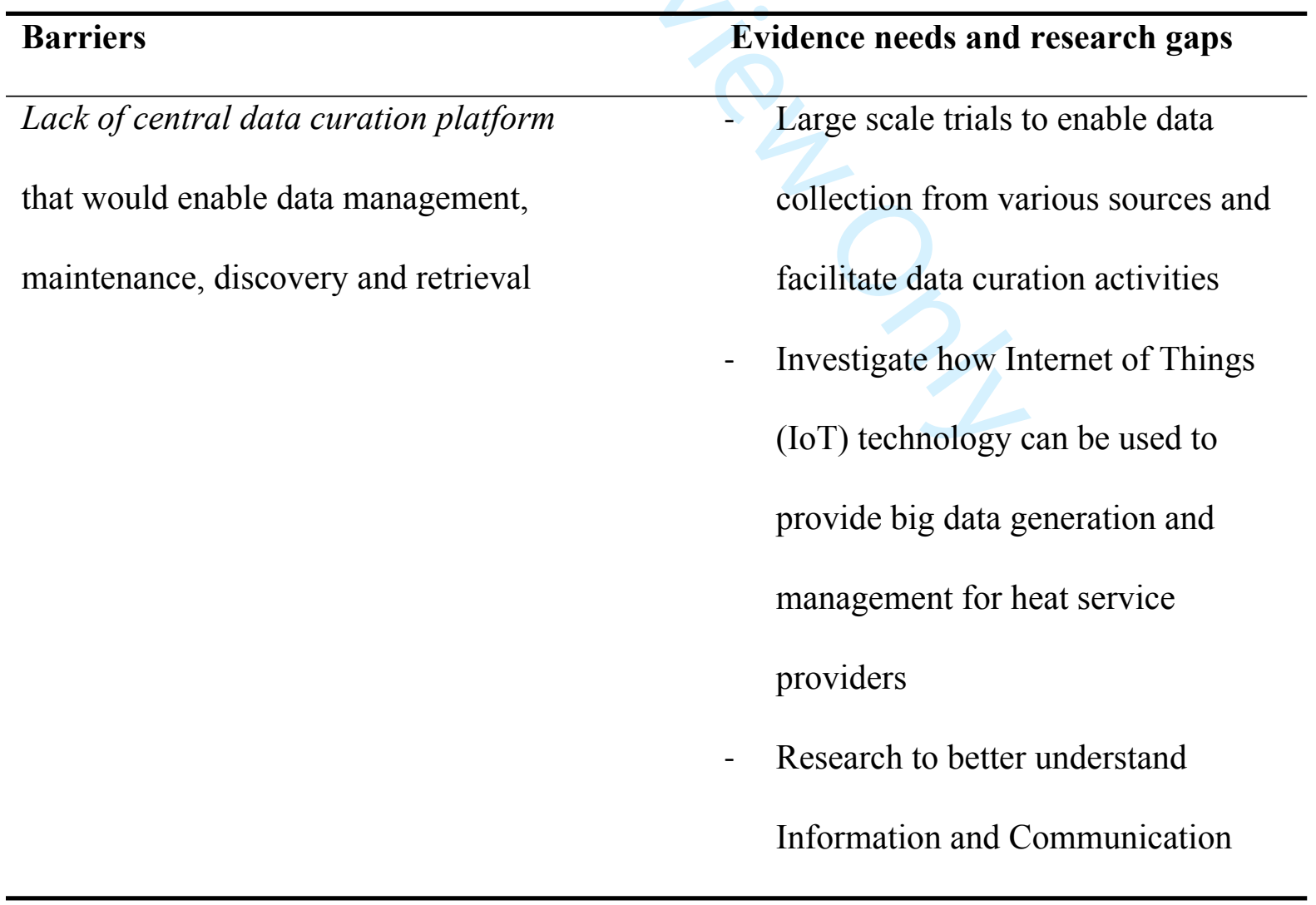


Evidence needs and research gaps

Technology (ICT) needs related to

data and suitable communication

systems, understanding of how much

data is needed, how often data needs

to be collected and transmitted, and

which communication technology is

the most suitable.

Barriers to learning

- Increased research and data sharing

Much of the data being generated in

by universities, NGOs and

relation to HaaS is held by utilities and

Governments.

not shared more widely due to

commercial sensitivity

Data privacy

Exploration of solutions to protect

consumer data from

unauthorisedunauthorized access or

disclosure

Cybersecurity of HaaS digital

- Explore solutions to protect HaaS

infrastructure

digital infrastructure against

confidentiality, integrity, and

availability attacks. These attacks

could be unintentional or intentional

cyber-attacks such as Denial of 
Barriers

Evidence needs and research gaps

Service attack to make heat services

unavailable.

Interoperability of data and technology

Rate of change in Information and

Communications Technology (ICT) is

higher than low carbon heating services,

which could cause problems both for

consumers and providers

Limited (skilled) installer and technician

capacity

- Development of industry guides on

installation of low carbon

technologies
1

\subsection{Novel business models and financing}

3 Novel business models can offer new value propositions for the consumer, unlock the market

4 to new technology companies, and generate new revenue streams. Access to finance to fund 
1 heat decarbonisationdecarbonization is a key issue for homeowners and while HaaS business

2 models have been identified as helping to address these challenges through enabling the

3 packaging of heat and asset costs in a long-term contract, it is as yet unclear whether such

4 models will be attractive to consumers or viable for suppliers.

5 Additionally, there is limited understanding of the interactions between HaaS and other

6 evolving business models such as peer to peer or time-of-use tariffs. While some studies seek

7 to compare consumer attitudes across a range of emerging business models (such as Crisp

8 and Kruja 2019), most studies tend to be relatively small scale and assess consumer

9 preferences based on abstracted descriptions of business models, rather than providing

10 participants with tailored scenarios based on actual consumption and housing types.

11 Similarly, there is significant interest in the potential for households with smart controls,

12 domestic generation technologies, storage, or other ability to shift demand, to play a

13 significant role in balancing high variable renewables systems. Incentivising Incentivizing

14 such flexibility services would require consumers to shift demand either electively (i.e.,

15 householders receive alerts about price changes and choose whether to adjust demand) or

16 through automated processes and it is currently unclear how such arrangements would

17 interact with HaaS contracts.

19 Table 5 stmmarisessummarizes the barriers, evidence needs, and research gaps around news

20 business models and financing. The barriers identified during the workshop relate to asset

21 ownership, house retrofit investability, access to finance for low carbon technologies,

22 competition between suppliers and investor confidence in the security of revenue

23 streams. [Table 5 near here] 
Table 5. Novel business models and financing

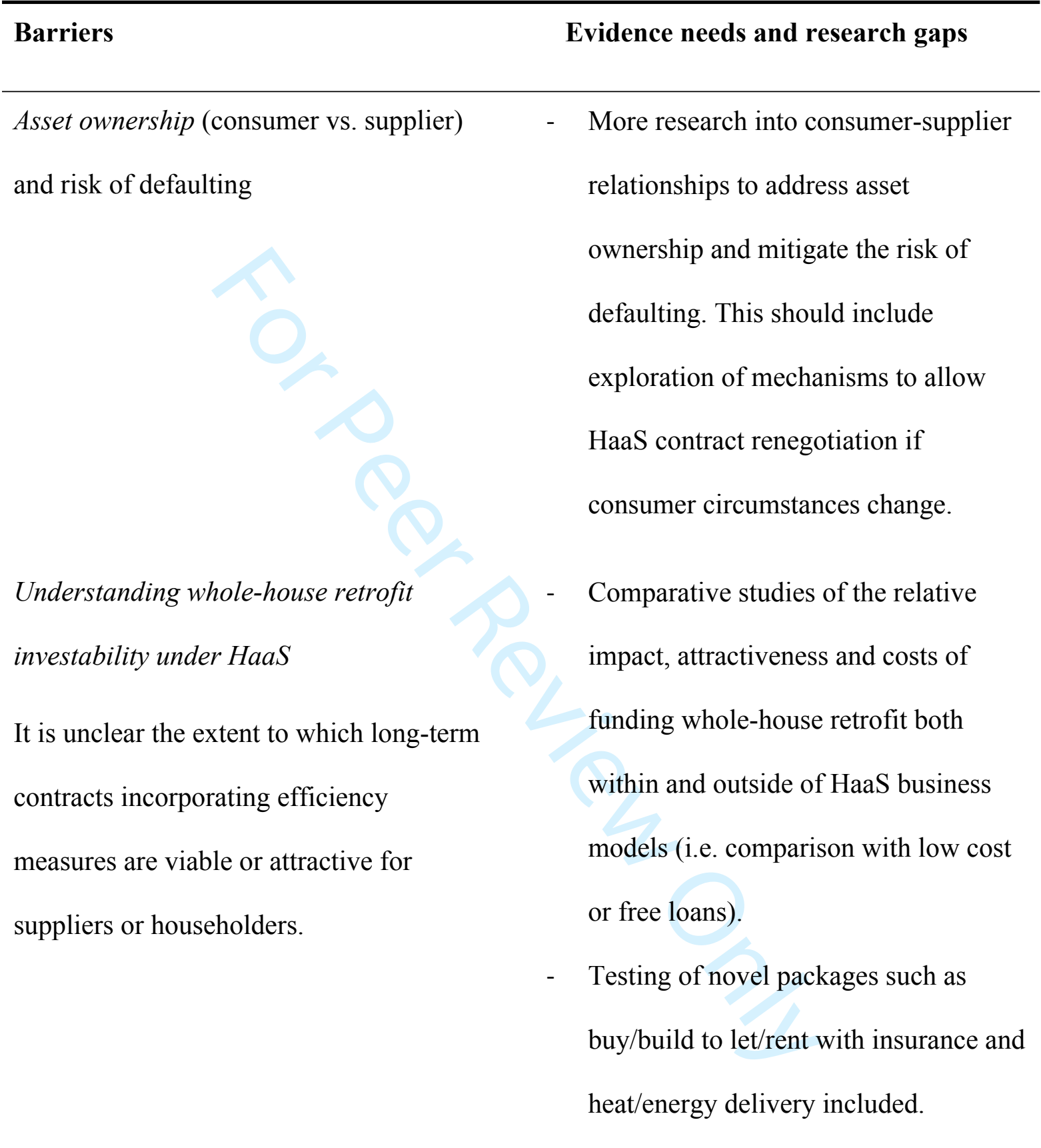


Lack of finance to enable low carbon technology

There is limited access to finance and incentives and government grants are essential

Investor confidence in security of revenue stream

There is a perception that low carbon technologies will increase bills especially in the private rented sector
- TriallingTrialing of interest free loans from government to enable low carbon technologies and support heat decarbonisationdecarbonization

- Studies of how different forms of asset financing (separate commercial loan, integrated in long-term contract, government backed loan etc.), impact on HaaS viability and outcomes

- Comparative studies of the development of HaaS models across different countries, and regulatory contexts, as well as the benefits and challenges of different varieties of HaaS. Learning from other servicebased sectors (broadband, telecoms) to increase investor confidence

- Develop a value proposition for HaaS that guarantees energy bills would not go up compared to the traditional energy as a commodity model 


\section{6. Conclusions and policy recommendations}

2 With the urgent need to meet global carbon reduction targets, Heat as a Service business

3 models present an innovative approach to accelerating decarbonisationdecarbonization via a

4 consumer-focussedfocused energy service that provides heating alongside the use of smart

5 systems and low carbon technologies. However, lessons from UK trials and insights from

6 stakeholders suggest that for HaaS to make a viable contribution to

7 decarbonisationdecarbonization, a number of barriers related to behaviourbehavior change,

8 policy, technology and financing need to be overcome. As analysis of stakeholder views and

9 existing literature indicates, there are a number of evidence needs, research gaps, as well as

10 opportunities that need to be explored around HaaS. Here, we summarisesummarize findings

11 and propose recommendations for policy that could enable the uptake of HaaS business

12 models and maximisemaximize its potential contribution to decarbonisationdecarbonization.

\subsection{Uncertainties around consumer preference, building performance, and policy} frameworks, limit HaaS uptake

16 Whilst there is considerable policy and industry interest in the potential to develop service-

17 based heating business models, there remains limited knowledge about the potential for such

18 models to accelerate uptake of decarbenisedecarbonized heating systems. In theory, the more

19 granular understanding of consumer preferences and building performance required to offer

20 HaaS could also enable businesses to offer tailored contracts that incorporate energy

21 efficiency retrofit and decarbonisedecarbonized heating technologies. However, there

22 remains significant uncertainty regarding how to manage risks between the supplier and

23 consumer, and in financing such offers. 
1 Similarly, despite the potential for HaaS business models to deliver better consumer comfort

2 and simplify future energy markets, it is important to note that many national policies and

3 programmes to decarbonisedecarbonize heat are underperforming or under-ambitious. For

4 example, in the UK, the Renewable Heat Incentive has delivered significantly lower numbers

5 of low carbon heating systems than anticipated. This is largely due to the need for

6 householders to provide upfront capital and limited consumer awareness of technologies. Yet,

7 there is considerable consensus that a more ambitious approach is required (Connor et al.

8 2015; Committe on Climate Change 2019; Lowes et al. 2020). Without comprehensive policy

9 frameworks to support the roll out of new heating technologies, the extent to which HaaS

10 business models will deliver decarbonisationdecarbonization is unclear.

11 The development of HaaS is also dependent on developing a much more detailed

12 understanding of building energy use and consumer behaviourbehavior. This includes the

13 integration of quantitative and qualitative research findings into energy simulation tools,

14 analysis of the impact of interior design (space layout, fixtures and fittings) on occupants'

15 behaviourbehavior and the use of psychological-cognitive behaviourbehavioral methods

16 (Delzendeh et al. 2017). The development of local flexibility services and markets also has

17 the potential to have a significant impact on the viability of decarbonisedecarbonized HaaS

18 offerings.

19 As discussed in Section 2, experiences of 'comfort' in relation to domestic heating are

20 influenced by a complex range of social and cultural factors. Emerging literature is beginning

21 to explore how heating preferences and practices might evolve as smart controls become

22 commonplace (see Sovacool et al. 2020a, 2020b, 2020c) however, there is a need to further

23 explore these dynamics in relation to decarbonized heating systems. Current experimentation

24 with HaaS business models is only just beginning to explore how conceptions of comfort 
1 may change as alternative heating and cooling technologies are adopted.For example, while

2 the ESC Smart Systems \& Heat programme indicated that most participants chose to heat

3 fewer rooms, none of these households had installed a heat pump where differences in the

4 operation of the heating system have the potential to change perceptions of comfort and/or

5 heating practices.

\section{$6 \quad 6.2$ More trials are needed to address consumer concerns and lack of understanding of}

$7 \mathrm{HaaS}$

8 Understanding the complex factors influencing energy behaviourbehaviors and use are likely

9 to be central to developing viable HaaS models which are viable and minimiseminimize the

10 risk of not meeting customerconsumer service commitments are priced correctly. This will

11 require extensive data on building and consumer archetypes as well as from connected home

12 devices.

13 Accordingly, addressing concerns around trust, energy service provision, and lack of

14 understanding of HaaS will require more trials that consider different consumer groups and

15 their motivations. This can allow HaaS providers to offer tailor-fit solutions with a variety of

16 technology options and financing plans that address risks for both suppliers and consumers.

17 As energy systems become smarter and more connected there is also a need for policymakers

18 and regulators to develop a much more detailed understanding of consumer archetypes, to

19 support this any publicallypublicly-funded HaaS trials should ensure that detailed analysis is

20 made widely available. 


\subsection{HaaS requires supportive policies for market development and regulation}

2 There is consensus among stakeholders that stronger policy strategies are needed for heat

3 decarbonisationdecarbonization. Specifically, for HaaS, current market regulations are

4 restrictive and not set-up for delivering smart energy services (e.g., in terms of supply

5 licensing, tariffs, lack of government subsidies and incentives for homeowners and tenants).

6 These limit consumer uptake and pose risks to current and potential suppliers, who are

7 already faced with the challenge of finding in offering economically viable solutions to offer

8 HaaS models. Supportive market policies will therefore be necessary to incentiviseincentivize

9 suppliers to incorporate efficiency measures and decarbonisedecarbonized heating

10 technologies into HaaS_-business models.

11 There is also a need for further research on the equity implications of HaaS models. As

12 identified by Sovacool, Lipson and Chard (2019) there is significant potential for HaaS

13 models to exclude some consumers from being offered contracts. Whilst the Energy

14 Technologies Institute (Energy Technologies Institute 2018b) have argued that HaaS models

15 could be compatible with fuel poverty programmes if government subsidies were targeted

16 based on service targets (thermal comfort and affordability), such an approach relies on

17 governments developing policy measures to address the potential exclusion of some

18 householders.

19 6.4 Open, interoperable, and secure data are key to deploying HaaS

20 Alongside technology-related challenges such as the effect of electrifying heat on power

21 networks and limited skilled capacities for installing low carbon technologies, HaaS is faced 
1 with data management issues in terms of data privacy, openness, interoperability between

2 systems, and lack of a central platform curating data.

3 There is a clear need to ensure that data used in delivering HaaS is open, interoperable, and

4 secure. Data openness needs to balance issues of consumer trust, incentivisingincentivizing

5 energy service retailers to invest in consumer relationships and allowing competition in

6 service offerings. These complex commercial and consumer issues need to be further

7 understood and linked to debate of data use by wider ICT erganisationsorganizations (Energy

8 Technologies Institute 2018a).

\subsection{Best practice energy services from other countries can inform HaaS development}

10 With HaaS only beginning to gain attention in many countries, there is considerable scope for

11 learning from European countries that have offered business models branded as HaaS. As

12 discussed in Sections 2 and 3.2, there is ambiguity in relation to defining Heat as a Service

13 business models and further comparison of different interpretations of the model could

14 provide learning. For instance, Best Green in Denmark offers asset leasing with a

15 performance and savings guarantee; whilst Thermondo in Germany offers consumers a

16 package comprising asset leasing, heat delivery, maintenance and insurance. The Energy

17 Systems Catapult in the UK are triallingtrialing an outcome based 'warm hours' model and

18 Eneco, in the Netherlands, are triallingtrialing what Delta EE (Delta EE 2019b) describe as a

19 fully outcome based HaaS model where agreed temperatures are delivered by a heat pump for 20 a fixed monthly fee. 
16.6 To facilitate HaaS, opportunities for consumers, experts, and industry to work together

$2 \quad$ should be explored

3 Across discussions on behaviourbehavior change, policy, technology, and financing, HaaS

4 stakeholders emphasisedemphasized the need for partnerships, specifically the need to

5 connecting installers, consumers, and suppliers in order to facilitate HaaS. This entails

6 sharing insights about what does/doesn't work_s and does not work-and improving the

7 dialogue amongst government, industry, academia and consumers. These, together with the

8 other opportunities and solutions explored in this paper could potentially enable HaaS to play

9 a much wider role in heat decarbonisationdecarbonization.

\section{References}

Adwek, George, Shen Boxiong, Paul O. Ndolo, Zachary O. Siagi, Chebet Chepsaigutt, Cicilia M. Kemunto, Moses Arowo, John Shimmon, Patrobers Simiyu, and Abel C. Yabo. 2019. The Solar Energy Access in Kenya: A Review Focusing on Pay-As-You-Go

Amelang, Sören. 2019. "Heating Start-up Thermondo Aims to Be Leading Energy Supplier." Clean Energy Wire. March 2019. https://www.cleanenergywire.org/news/heating-startthermondo-aims-be-leading-energy-supplier. Acessed 11 February 2020.

Andersen, Rune Korsholm. 2012. “The Influence of Occupants' Behaviour on Energy International Conference on Healthy Buildings.

Bates, James S. 2016. "What's Ketso? A Tool for Researchers, Educators, and Practitioners." 
1

2

3

4

5

6

7

8

9

10

11

12

Journal of Human Sciences and Extension 4 (2).

BEIS. 2018a. “A Future Framework for Heat in Buildings: Call for Evidence Government Response.” London, Department for Business, Energy and Industrial Strategy. https://assets.publishing.service.gov.uk/government/uploads/system/uploads/attachment _data/file/762546/Future_Framework_for_Heat_in_Buildings_Govt_Response_2_.pdf. . 2018b. "Clean Growth - Transforming Heating - Overview of Current Evidence." https://assets.publishing.service.gov.uk/government/uploads/system/uploads/attachment _data/file/766109/decarbonisingdecarbonizing-heating.pdf.

Bolton, Ronan, and Matthew Hannon. 2016. “Governing Sustainability Transitions through Business Model Innovation: Towards a Systems Understanding.” Research Policy 45 (9): 1731-42. https://doi.org/10.1016/j.respol.2016.05.003.

Booth, Adrian, Niko Mohr, and Peter Peters. 2016. "The Digital Utility: New Opportunities and Challenges." Electric Power \& Natural Gas. McKinsey \& Company.

Boza-Kiss, A Toleikyté, and P Bertoldi. 2019. "Energy Service Market in the EU: Status Review and Recommendations 2019.” Luxembourg. EU Commission, https://doi.org/10.2760/768.

Brown, Donal, Steve Sorrell, and Paula Kivimaa. 2019. "Worth the Risk? An Evaluation of Alternative Finance Mechanisms for Residential Retrofit.” Energy Policy 128 (November 2018): 418-30. https://doi.org/10.1016/j.enpol.2018.12.033.

Bryant, Scott T., Karla Straker, and Cara Wrigley. 2018. “The Typologies of Power: Energy Utility Business Models in an Increasingly Renewable Sector.” Journal of Cleaner Production. https://doi.org/10.1016/j.jclepro.2018.05.233.

Capelo, C., J. Ferreira Dias, and R. Pereira. 2018. “A System Dynamics Approach to Analyse the Impact of Energy Efficiency Policy on ESCO Ventures in European Union Countries: A Case Study of Portugal.” Energy Efficiency 11: 893-925. 
1 https://doi.org/https://doi.org/10.1007/s12053-018-9617-9.

2 Chard, Rose, Matthew Lipson, Jody Osborn, and Shenay Kinyok. 2019. "Designing Smarter 3 Consumer Protection in a Smarter Energy World: Using Field Trials.” Citizens Advice, $4 \quad$ London.

5 Chaudry, Modassar, Muditha Abeysekera, Seyed Hamid Reza Hosseini, Nick Jenkins, and 6 Jianzhong Wu. 2015. "Uncertainties in DecarbonisingDecarbonizing Heat in the UK." 7 Energy Policy 87 (December): 623-40. https://doi.org/10.1016/J.ENPOL.2015.07.019.

8 Christensen, Toke Haunstrup, and Freja Friis. 2017. “Case Study Report Denmark: Findings from Case Studies of ProjectZero, Renewable Energy Island Samso and Innovation

11 Cleary, Kathryne, and Karen Palmer. 2019. "Energy-as-a-Service : A Business Model for Expanding Deployment of Low-Carbon Technologies." Washington DC.

Committe on Climate Change. 2019. "Net Zero: The UK's Contribution to Stopping Global

$$
\text { Warming." London }
$$

Committee on Climate Change. 2019. "Reducing UK Emissions - 2019 Progress Report to Parliament." 2019 Progress Report to UK Parliament. London, Committee on Climate Change.

Connor, Peter M., Lei Xie, Richard Lowes, Jessica Britton, and Thomas Richardson. 2015. “The Development of Renewable Heating Policy in the United Kingdom.” Renewable Energy 75: 733-44. https://doi.org/10.1016/j.renene.2014.10.056.

Crisp, Tom, and Krista Kruja. 2019. "Future for All Making a Future Retail Energy Market Work for Everyone.” London, Citizens Advice.

Day, Rosie, Gordon Walker, and Neil Simcock. 2016. “Conceptualising Energy Use and Energy Poverty Using a Capabilities Framework.” Energy Policy. https://doi.org/10.1016/j.enpol.2016.03.019. 
1 DellaValle, Nives. 2019. "People’s Decisions Matter: Understanding and Addressing Energy

2

3

4

5

6

7

8 Poverty with Behavioral Economics.” Energy and Buildings. https://doi.org/10.1016/j.enbuild.2019.109515.

Delta EE. 2019a. "How Accessible Are Future Energy Supply Business Models? A Report for Citizens Advice." London.

—.2019b. "Heat as a Service." https://www.deltaee.com/images/Infographics/HaaS_Infographic_Final.pdf. Accessed 21 January 2020.

Delzendeh, Elham, Song Wu, Angela Lee, and Ying Zhou. 2017. “The Impact of Occupants' Behaviours on Building Energy Analysis: A Research Review.” Renewable and Sustainable Energy Reviews 80 (September 2016): 1061-71. https://doi.org/10.1016/j.rser.2017.05.264.

Energy Systems Catapult. 2019a. "Delivering an Effective Field Trial: Lessons from the Living Lab.” Birmingham, ESC.

—. 2019b. "Enabling Domestic Interoperability: Insight Report.” Birmingham.

—. 2019c. "Field Trial Learnings: Insight Report.” Birmingham, ESC.

—. 2019d. "Heat as a Service: An Introduction." Birmingham. ESC.

—.2019e. "Heat as a Service Case Study Whole System Implications of Heat as a Service Business Model for Demand-Side Management of Electric Heating Demands-." Birmingham, ESC.

_. 2019f. "Smart Systems and Heat Programme: Phase 2 Summary of Key Insights and Emerging Capabilities.” Birmingham, ESC.

—. 2020. "Baxi and Bristol Energy Trial Heat-as-a-Service with an Eye towards Zero Carbon.” ESC News, February 2020. https://es.catapult.org.uk/news/baxi-and-bristolenergy-heat-services/. Accessed 26 February 2020.

Energy Technologies Institute. 2018a. “Domestic Energy Services.” Loughborough, ETI. 
1

2

3

4

5

6

7

8

9

10

11

12

13

14 .2018b. "How Can People Get the Heat They Want At Home, Without the Carbon?" Loughborough, ETI.

—. 2019. “The Journey to Smarter Heat.” Loughborough, ETI-www.eti.co.uk.

European Commission. 2016. “COMMUNICATION FROM THE COMMISSION TO THE EUROPEAN PARLIAMENT, THE COUNCIL, THE EUROPEAN ECONOMIC AND SOCIAL COMMITTEE AND THE COMMITTEE OF THE REGIONS. An EU Strategy on Heating and Cooling.” Brussels, Belgium. https://doi.org/10.1017/CBO9781107415324.004.

European Council. 2018. Directive (EU) 2018/2001 of the European Parliament and of the Council on the Promotion of the Use of Energy from Renewable Sources (Recast). Brussels, Belgium. European Union.

Fell, Michael James. 2017. "Energy Services: A Conceptual Review.” Energy Research and Social Science 27: 129-40. https://doi.org/10.1016/j.erss.2017.02.010.

Fujimori, S., M. Kainuma, T. Masui, T. Hasegawa, and H. Dai. 2014. “The Effectiveness of Energy Service Demand Reduction: A Scenario Analysis of Global Climate Change Mitigation.” Energy Policy. https://doi.org/10.1016/j.enpol.2014.09.015.

Hall, Stephen, Christoph Mazur, Jeffrey Hardy, Mark Workman, and Mark Powell. 2020. "Prioritising Business Model Innovation: What Needs to Change in the United Kingdom Energy System to Grow Low Carbon Entrepreneurship?” Energy Research and Social Science. https://doi.org/10.1016/j.erss.2019.101317.

Hanna, R F, R Gross, and B Parrish. 2016. "Best Practice in Heat DecarbonisationDecarbonization Policy: A Review of the International Experience of Policies to Promote the Uptake of Low-Carbon Heat Supply." UKERC Technology and Policy Assessment. London.

Hannon, Matthew J., and Ronan Bolton. 2015. "UK Local Authority Engagement with the 
1 Energy Service Company (ESCo) Model: Key Characteristics, Benefits, Limitations and

$2 \quad$ Considerations." Energy Policy 78: 198-212.

$3 \quad$ https://doi.org/10.1016/j.enpol.2014.11.016.

4 Hannon, Matthew J., Timothy J. Foxon, and William F. Gale. 2013. "The Co-Evolutionary

5 Relationship between Energy Service Companies and the UK Energy System:

6 Implications for a Low-Carbon Transition.” Energy Policy, no. 61: 1031-45.

7 IEA. 2019. “Renewables 2019.” Paris, France. International Energy Agency.

8 IPCC. 2018. "Summary for Policymakers.” Edited by V Masson-Delmotte, P Zhai, H. O.

Kalt, Gerald, Dominik Wiedenhofer, Christoph Görg, and Helmut Haberl. 2019.

Pörtner, D. Roberts, J. Skea, P. R. Shukla, A. Pirani, et al. Global Warming of $1.5^{\circ} \mathrm{C}$. An

IPCC Special Report on the Impacts of Global Warming of $1.5^{\circ} \mathrm{C}$ above Pre-Industrial

Levels and Related Global Greenhouse Gas Emission Pathways, in the Context of

Strengthening the Global Response to the Threat of Climate Change,. Geneva.

"Conceptualizing Energy Services: A Review of Energy and Well-Being along the Energy Service Cascade.” Energy Research and Social Science 53 (November 2018):

17 Knobloch, Florian, Hector Pollitt, Unnada Chewpreecha, Vassilis Daioglou, and JeanFrancois Mercure. 2019. "Simulating the Deep DecarbonisationDecarbonization of Residential Heating for Limiting Global Warming to $1.5^{\circ} \mathrm{C} . ”$ Energy Efficiency 12 (2): 521-50. https://doi.org/10.1007/s12053-018-9710-0.

Lakatos, Edit, and Apostolos Arsenopoulos. 2019. "Investigating EU Financial Instruments to Tackle Energy Poverty in Households: A SWOT Analysis.” Energy Sources, Part B:

25 Lombardi, Mariarosaria, Pasquale Pazienza, and Roberto Rana. 2016. “The EU 
1 Environmental-Energy Policy for Urban Areas: The Covenant of Mayors, the ELENA

$2 \quad$ Program and the Role of ESCos.” Energy Policy 93 (December): 33-40.

3 https://doi.org/10.1016/j.enpol.2016.02.040.

4 Lowes, Richard, Jan Rosenow, Meysam Qadrdan, and Jianzhong Wu. 2020. "Hot Stuff:

5 Research and Policy Principles for Heat DecarbonisationDecarbonization through Smart

$6 \quad$ Electrification." Energy Research and Social Science 70 (December): 101735.

$7 \quad$ https://doi.org/10.1016/j.erss.2020.101735.

8 Morley, Janine. 2018. "Rethinking Energy Services: The Concept of 'Meta-Service' and 9 Implications for Demand Reduction and Servicizing Policy.” Energy Policy 122 (June): $10 \quad$ 563-69. https://doi.org/10.1016/j.enpol.2018.07.056.

11 Mulvey, Dawn, Nicole McNab, and Steve Morley. 2019. "Future Energy Models: Research 12 Findings Report.” London, Citizens Advice.

13 Nolden, Colin, Steve Sorrell, and Friedemann Polzin. 2016. "Catalysing the Energy Service 14 Market: The Role of Intermediaries.” Energy Policy 98: 420-30. $15 \quad$ https://doi.org/10.1016/j.enpol.2016.08.041.

16 Rai, V., D. C. Reeves, and R. Margolis. 2016. "Overcoming Barriers and Uncertainties in the 17 Adoption of Residential Solar PV.” Renewable Energy 89: 498-505.

18 Sarangi, Smruti R., Partha Dutta, and Komal Jalan. 2012. "IT Infrastructure for Providing 19 Energy-as-a-Service to Electric Vehicles.” IEEE Transactions on Smart Grid 3 (2): 20 594-604. https://doi.org/10.1109/TSG.2011.2175953.

21 Seebauer, Sebastian, Michael Friesenecker, and Kristina Eisfeld. 2019. "Integrating Climate 22 and Social Housing Policy to Alleviate Energy Poverty: An Analysis of Targets and 23 Instruments in Austria." Energy Sources, Part B: Economics, Planning, and Policy 14 24 (7-9): 304-26. https://doi.org/10.1080/15567249.2019.1693665.

25 Selim, Mohamed Y., Ahmad Alsharoa, Ahmed E. Kamal, and Mohammed Abdullah 
1

2

3

4

5

6

7

8

9

10

11

12

13

14

Alnuem. 2017. "SURE: A Novel Approach for Self Healing Battery Starved Users Using Energy Harvesting." IEEE Access 5: 6110-20. https://doi.org/10.1109/ACCESS.2017.2672958.

Shove, Elizabeth. 2003. Comfort, Cleanliness and Convenience. The Social Organisation of Normality. Oxford: Berg, Oxford.

Skovshoved, Stina, and Isabelle Sandqvist. 2017. "Customer Value Driven Service Innovation: Identifying Service Opportunities in the Residential Heating Market Based on Customers' Value Preferences.” Linköping, Sweden. Linköpings Universitet.

Sorrell, Steve, and John Dimitropoulos. 2008. "The Rebound Effect: Microeconomic Definitions, Limitations and Extensions.” Ecological Economics. https://doi.org/10.1016/j.ecolecon.2007.08.013.

Sovacool, Benjamin K., Matthew M. Lipson, and Rose Chard. 2019. “Temporality, Vulnerability, and Energy Justice in Household Low Carbon Innovations.” Energy Policy. https://doi.org/10.1016/j.enpol.2019.01.010.

Sovacool, Benjamin K., and Mari Martiskainen. 2020. "Hot Transformations: Governing Rapid and Deep Household Heating Transitions in China, Denmark, Finland and the United Kingdom.”Energy Policy. https://doi.org/10.1016/j.enpol.2020.111330.

State of Green. 2018. "From Policy to Action: Implementation of the European Energy Union.” Copenhagen, Denamrk. State of Green.

—. 2020. "Best Green.” 2020. https://stateofgreen.com/en/partners/best-green/. Accessed 16 January 2020.

Strydom, Adél, Josephine Kaviti Musango, and Paul K. Currie. 2020. “Connecting Energy Services, Carriers and Flows: Rethinking Household Energy Metabolism in Cape Town, South Africa." Energy Research and Social Science. https://doi.org/10.1016/j.erss.2019.101313. 
1 Suhonen, Niko, and Lasse Okkonen. 2013. "The Energy Services Company (ESCo) as 2 Business Model for Heat Entrepreneurship-A Case Study of North Karelia, Finland.” 3 Energy Policy 61 (October): 783-87. https://doi.org/10.1016/j.enpol.2013.06.047. 4 Wengel, Yana, Alison McIntosh, and Cheryl Cockburn-Wootten. 2019. "Co-Creating $5 \quad$ Knowledge in Tourism Research Using the Ketso Method." Tourism Recreation $6 \quad$ Research 44 (3): 311-22. https://doi.org/10.1080/02508281.2019.1575620.

\section{7}

8 